\title{
Application of National Symbols in Modern Furniture Design
}

\author{
Yingyan Guo \\ Sichuan Polus International College \\ Chengdu, China 610103
}

\begin{abstract}
This article takes the example of the extraction and application of liangshan Yi people's Traditional decoration colors, decorative motifs and decorative patterns, analyzes the extraction process and methods of national decorative symbol, and explains some ideas on how to apply national symbol into modern furniture design as an important design element, in order to provide some theoretical support to modern furniture which meet modern design aesthetic and with national characteristics.
\end{abstract}

Keywords-national symbols; Liangshan Yi people; decorative symbol; furniture design

\section{INTRODUCTION}

Contemporary furniture design trend shows the internationalization and nationalization two kinds of situation. Due to the development of modern information technology, convenience of transport, open of international markets and international trade, the cultural communication between the regions and nations has been strengthened. So the furniture styles tend to be the same is an inevitable trend. At the same time, furniture designers further realized the value of the national culture, "what belongs to the nations belongs to the world " is agreed by more and more people, people has became the basic point for contemporary furniture design to the world. Our country is a multiracial country, each nation has a variety of decorative symbols, in different regions and different nations, these symbols have their own national culture characteristics and aesthetic imagery, this article takes the extraction and application of Liangshan Yi people 's traditional decorative symbol as an example, to explore ways and means for innovative modern furniture design.

\section{EXTRACTION OF NATIONAL SYMBOL}

National symbol is mainly from various valuable design experience and design elements in China's traditional culture, which is the accumulation during long history of Chinese civilization development process. It includes color, shape, pattern, etc., we use these symbols in the design practice and incorporate them into modern furniture design. Through the whole design process, we should first extract specific and clear symbol element as an important point for furniture design. Here we take the extraction of the Yi people's traditional decorative symbol which has distinctive regional

Subject Source: Yi people Culture Research Center project (YZWH1334) in Sichuan Province philosophy and social science research base and Sichuan Province Education Department of Humanities and social science research base - " Research and development of modern national furniture design based on Liangshan Yi people decorative symbols". characteristics and national features as an example, analyze the ideas and methods to extract national symbols.

\section{A. Extraction of the Traditional Decorative Colors}

Color as one of decorative symbols, and has the most geographical characteristics and national features, is the focal point during the design of modern national furniture. Through the observation and analysis of Yi people's traditional objects "Fig. 1", "Fig. 2", "Fig. 3", we can see the black, red, yellow three beautiful colors are the soul of Yi people's traditional color, they are the main colors Yi people's traditional artifacts which directly show the rich and colorful national style of Yi people. It is mainly because in Yi people, these three colors were given a special symbolic meaning. Yi people advocate black color, partly because the influence of the surrounding environment, on the other hand is mainly related to the Yi people's hierarchy, black symbolizes the noble black Yi people. Yi people advocate red color, mainly due to the respect of "fire", Yi people has such a proverb: "Born at fireplace, died on the fire", "fire" brought warmth, light, and even good fortune to Yi ancestors, thus creating Yi people's advocate emotion to the fire. The yellow color as a symbol of the sun, represents abundance, harvest and gorgeous. Since Yi ancestors worship the sun, they believe the sunlight can shelter their ancestral spirits, yellow color are given a mysterious religious overtones by $\mathrm{Yi}$ people. In addition, on traditional artifacts of Yi people also often combined with white, green, blue three colors, white often go with black, green color can be seen as forest and plant color, blue color is the color of the sky, which are the common colors in Yi people's daily life, they can combined with black, yellow and red colors.

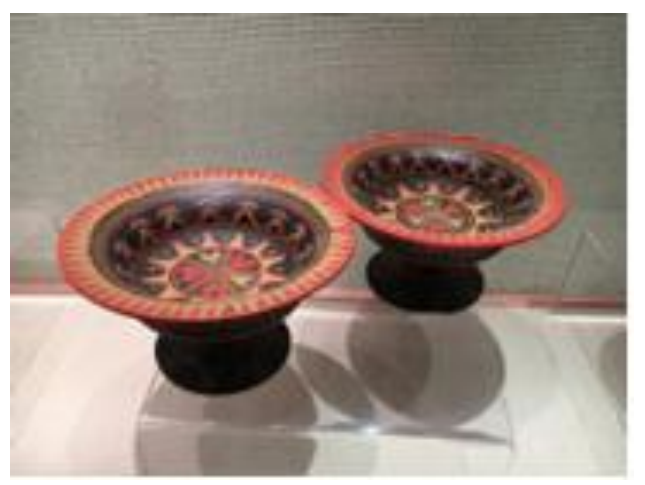

Fig. 1. Colors on Yi people's traditional artifacts (taken in Liangshan Yi slave society museum) 


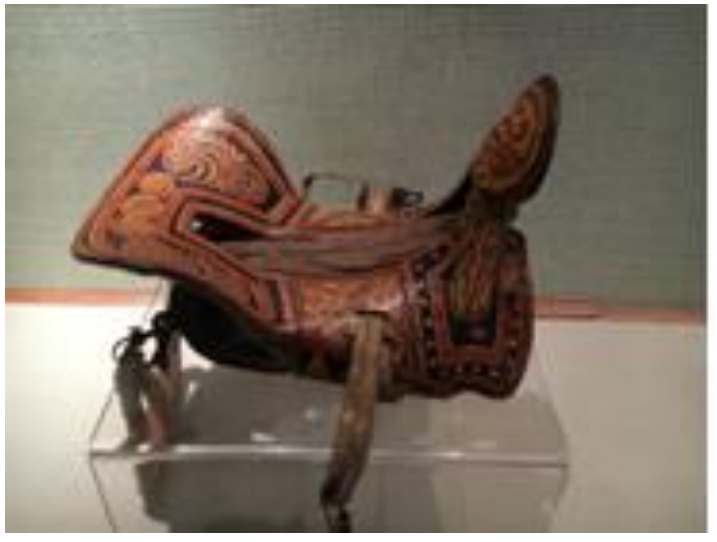

Fig. 2. Colors on Yi people's traditional artifacts (taken in Liangshan Yi slave society museum)

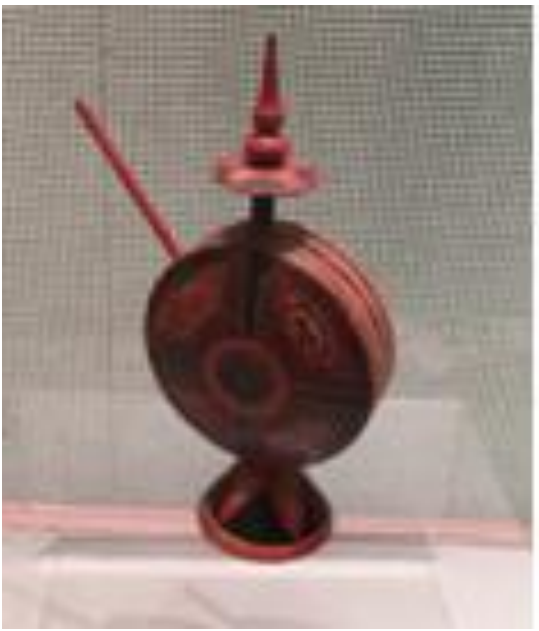

Fig. 3. Colors on Yi people's traditional artifacts (taken in Liangshan Yi slave society museum)

\section{B. Extraction of Traditional Decorative Patterns}

On various traditional architecture, furniture, clothing and lacquer from all nations, we can see a wide range of colorful decorative patterns. Because the subjects of these patterns generally derived from nature and daily life, so they are often with strong regional characteristics. Through the research of a large number of Yi people's traditional artifacts, we have found that Yi people's traditional decorative pattern mainly reflect the worship for nature and totem. These patterns according to their way of expression, can be divided into two types: one is a more emotional bionic pattern with nature animals, plants and natural landscape as the prototype, applied in the decorative patterns of objects surface after appropriately artistic treatment, such like sheep eye pattern, horn pattern and others; it is worth mentioning that the animal pattern has prominent position in Liangshan $\mathrm{Yi}$ people's traditional decorative patterns, not only because of its decorative effect, but also may reflect the worship of so me some totems by $\mathrm{Yi}$ people, such as black tiger pattern is come from the tiger totem worship. The other type is more rational geometric patterns, such as triangles, dots (circles), weaving pattern, wavy lines, 米-shaped pattern and so on. But the difference between pictographic decorative pattern and geometric decorative pattern is not absolute, former is one of the foundations of the latter, and both of them are the result of observation and imitation of things.

\section{Extraction of Traditional Decorative form Elements}

Furniture as an important interior furnishing, its form and style should be consistent with surrounding buildings and interior environment, so the form of traditional building is one of the main sources for us to get the design inspiration. Traditional Architecture of Liangshan Yi region generally with wooden structure, it uses wood as beam, mutual plugs form a tree-shaped support structure, some of the architecture use shan-jia structure as the skeleton, their production process is exquisite [1]. Decoration of traditional dwellings mainly in the entrance gate and outside eaves, the detailed eave member mostly use buffalo horn shape, the overall shape of the trend showed a growth trend of bamboo "Fig. 4". As it can be seen, because use a lot of wood, determines the shape and structure of Yi people's traditional architecture and furniture. Traditional buildings in Liangshan Yi region are generally small, which is mainly affected by the climatic conditions in Yi Region. The furniture is an important part of the indoor environment, in order to coordinate with the environmental space, Yi people's traditional furniture has also created characteristics of small-scale and short. In Liangshan Yi people's traditional furniture, in addition to food storage lockers sometimes maybe produced with a large size based on the demand, others generally are small size, such as low tables, stools, beds and so on. Of course, small scale of Yi people's furniture is also influenced by the living habits, economic conditions and materials.
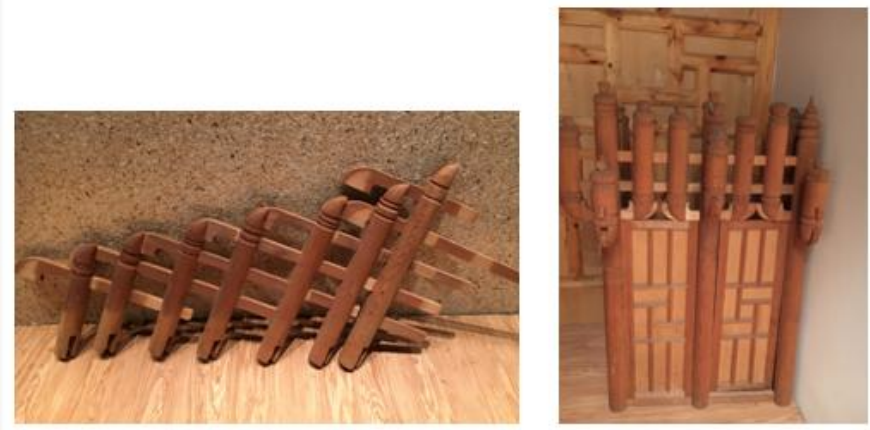

Fig. 4. Decorative form of Yi people's traditional architecture (taken in Liangshan Yi slave society museum)

\section{APPLICATION OF NATIONAL SYMBOL IN MODERN NATIONAL FURNITURE DESIGN}

With the improvement of material life level, the demand for furniture aesthetic functions are increasing, culture and nationality of furniture are paid more and more attention. In the design of furniture, we should focus on the heritage and innovation of national symbol, combine the essence of traditional and national culture with characteristics of the times, through the form, color, pattern and other elements of furniture products to convey the cultural connotations to the public, so 
as to meet the public culture and national emotion demand for the furniture.

\section{A. Application of Traditional Decoration Color in Modern National Furniture}

Traditional decoration color has distinctive geographical and cultural characteristics, which is historical accumulation result of the natural, social and aesthetic psychology. Black, red, yellow three colors as typical case of Yi people's decoration color, use these three colors in modern furniture's decorative colors and decorative patterns is the cultural heritage and development of Yi people's three-color culture. From the modern aesthetic point of view, the match of black and red has a strong visual impact, it is a relatively calm color combination and also is a classical match of modern decorative colors. The added yellow color brings some lively sense into the sedate black and red colors, which plays a very good decorative effect, so Yi people's color matching is a scientific nature. The designed furniture placed in the interior space with Yi people's characteristics, such as a dining space and a few special places for cultural tourism, it can add the ethnic customs to the indoor environment and increase the culture environment.

\section{B. Application of Traditional Decorative Patterns in Modern National Furniture}

In modern furniture, especially the selection and design of national furniture decorative patterns, on one hand we should try to retain the themes and forms of national traditional decorative patterns, which is a form of national cultural heritage, such as tiger totem, ram's horn and bull-eye patterns in Yi people's decorative patterns. On the other hand, we should also realize that time is changing, whether traditional decorative patterns could convey a modern aesthetic sense is particularly important for the innovative design of modern national furniture. Some of the traditional decorative patterns are complicated, and some decorations are too "heavy, full," do not meet the aesthetic needs of modern people, so we need to re-designed them. We can break up the complex decorative patterns, extract them separately and reassembling; or abstract and simplified them and redesign the patterns with modern aesthetic composition rules "Fig. 5". Use this kind of pattern to decorate furniture surface not only retain the traditional pattern symbol, also make this decorative arts come to modern life with a new attitude. It is the result of the traditional culture development and innovation, it is one of the effective ways for the tradition toward modern, it embodies the fashion that modern man pursuit simple and the idea that make the past serve the present.

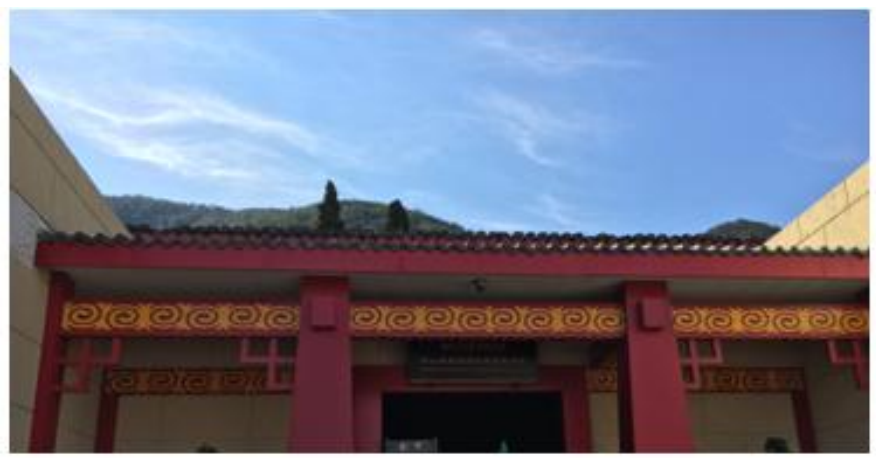

Fig. 5. Application of Yi people's traditional decorative patterns

Today's world shows a gradual integration and diversity, and cultures from all countries' influence with each other and mix together. Therefore, during "redesign" of the traditional decorative patterns, we can also extensively absorb foreign culture, combine decorative elements with different nature and different types together, through the recombination and reconstruction of the patterns to make it a unity of ancient and modern and also a unity of Chinese and foreign, which is the effective way to achieve modern furniture innovation.

For the performance of decorative pattern on modern furniture, I believe, on the one hand we can inherit and develop folk craftsman skill in order to meet the psychological needs of modern "back to nature"; on the other hand, we should make fully use of our modern technology and equipment to enhance and improve the visual performance results of these decorative patterns. For the decorative process aspects, besides of sculpture, painting, lacquer and other traditional crafts, we can use modern technologies like veneer, thermal transfer, decorative moldings and others.

\section{Application of Traditional Decorative form Element on Modern National Furniture}

When creating product form, normally the designers first need confirm a theme, the inspiration for this theme might be imitations of something, perhaps some story, the association produced by some event, or expressions to some feelings and ideas. Taking the Yi style furniture design as an example, we can select some representative Yi elements as a key point of design, such as Yi's "Fire", "buffalo horn" and other form symbols. Through abstract simulation and application of these elements to the furniture design, we can create a deep sense of national flavor to make people have unlimited reverie.

\section{CONCLUSION}

Our country is a multiracial country with a long history, excavation and study of their traditional culture and national culture connotation is an effective way for our innovative creation of modern furniture design. Extraction of these national symbols with distinctive regional characteristics and cultural features, carry out heritage and innovation in order to find ways and means to combine with the modern furniture design. It is requirement for modern furniture design trends and also the mission of Chinese designers. 


\section{REFERENCES}

[1] Song Laifu "System analysis of Liangshan Yi people's decorative art symbol " [D] Chengdu: Southwest Jiaotong University, 2010

[2] Liu Jie Study of Sichuan Liangshan Yi people's furniture modeling [D]. Nanjing: Nanjing Forestry University, 2008

[3] Li Cisheng The design features of Liangshan Yi people's building furniture [J] Furniture and Interior Decoration, 2010,9: 24-25.

[4] Zhang Yaoyin Design and refined presentation of traditional furniture cultural symbols [J] Packaging Engineering, 2013,34 (10): 36-38.

[5] Li Xiaoling Application of Yi people's decorative patterns in modern fashion product modeling art [J] Yihai, 2012,10: 100-101.

[6] Lv Jiufang Exploration of Innovative design in modern Chinese furniture [J] Packaging Engineering, 2012,33 (18): 35-37

[7] Zhang Qiumei Inheritance and Innovation of traditional folk furniture symbols [J] Packaging Engineering, 2009,30 (7): 115-116. 